
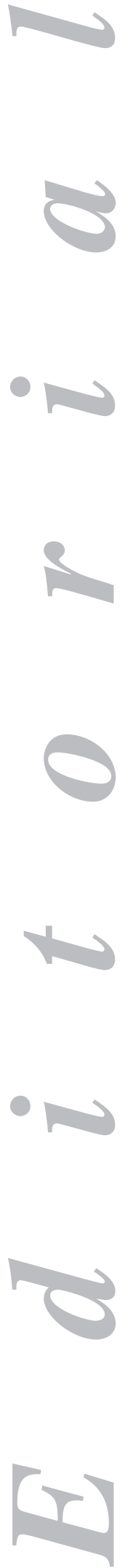

\title{
ERCP in a low-volume hospital. Arguments "for" and "against" this type of practice
}

\section{Dear reader,}

The current issue of Revista Española de Enfermedades Digestivas includes an interesting article by JM Riesco et al. entitled "Efficacy and safety of ERCP in a lowvolume hospital" (1). The Editorial Board of the journal wants to highlight this manuscript, not only for its high scientific level but also because of its clinical relevance and the controrversy it entails. The authors -who had no previous experience in performing endoscopic retrograde cholangiopancreatography (ERCP) and work in a lowvolume institution (fewer than 100 ERCPs/year)- show in this elegant study their learning curve with this technique. The results from the aforementioned study suggest that, should one adhere to the training recommendations published (2,3), the efficacy and safety levels described in the literature for ERCP may be reached.

Although one may find recommendations on this subject in the literature, different opinions exist regarding who should perform complicated techniques like ERCP, and which should be the minimum requirements needed by a hospital and/or an endoscopist in order to perform this highly complex technique with potential complications. These questions arise on each occasion this subject is discussed, and we hope that the arguments provided by Dr. López-Rosés and Dr. Rodríguez-Muñoz for and against-respectively- the performance of these complex techniques in low-volume institutions with little experience will help us determine whether this type of procedure is to be considered a "one-size-fits-all" approach or otherwise reserved for hospitals where experience does exist and volume is adequate in order to ensure success. Finally, in dealing with these issues we think aloud and raise the matter of credentialing endoscopy units and endoscopists performing these complicated techniques, and then auditing their results and complications periodically. Certainly, despite expert opinions, we believe that future interventions should point in that direction to secure our patients maximal guarantees.

\section{ERCP in low-volume hospitals - Arguments for (Leopoldo López-Rosés)}

ERCP represents one of the most complex digestive endoscopy techniques; it has a long learning curve, and is associated with a significant risk for complications, some of them severe or even lethal. However, due to its clinical usefulness, ERCP has progressively become widespread and is presently performed not only in big referral centers but also in smaller institutions with a low volume of patients. Determining who is really capable of performing ERCP, and which hospitals should be licensed to do it, is no doubt a requirement. It seems reasonable that not every endoscopist or hospital should be granted privileges to perform this procedure. On the one hand, apart from 
the long learning curve of the technique and as occurs with any other techniques, personal skill is required that not everyone may have. On the other hand, the number of ERCPs requested is limited and is simply not enough for all endoscopists. A study conducted in the United Kingdom a few years ago estimated that, for a population of 250,000 people, 180 ERCPs woul be needed annually, $75 \%$ of them therapeutic in nature. In the same study, the authors estimated that with all gastroenterologists performing ERCPs in the area, and assuming that the estimated proportion of specialists is 1 per 80,000 people, the number of ERCPs performed would be as low as 1 procedure per week and gastroenterologist (4).

ERCP is a difficult technique that requires long training, with progressive steps in which the goal of the procedure is gradually achieved. Most experts consider that a minimum of 200 procedures under the supervision of an experienced endoscopist are required to become competent in this technique. A number of studies have been able to prove that, as the number of ERCPs increases, success at cannulating the papilla of Vater improves from $43 \%$ at the beginning of the learning curve to $80 \%$ after 180 200 procedures have been completed (5-7). The same thing applies to other technical requirements like precut cannulation, stone extraction, or stent placement $(8,9)$.

The volume of procedures performed at each institution will determine that hospital's capability to teach the technique and offer ERCP to patients with the safety and efficiency required. In a study by Hellier (4) a minimum of 250 ERCP procedures per year were deemed to be required to obtain the credentials needed to teach ERCP. A number of publications have demonstrated that teaching ability, technical success, and complications are related to the number of procedures performed annually at each center. A recent survey conducted in the USA classified hospital ERCP volumes as high ( $>200$ per year), intermediate (50-200 procedures/year), and low ( $<50$ ERCP per year). In that study, $98 \%$ of fellows training at a high-volume hospital completed 180 ERCPs during their training, while only $58 \%$ of fellows at low-volume hospitals reached these numbers (10). In the same country, only $36 \%$ of fellows will achieve the minimum number required for competency (11). From a clinical point of view, it is a well established fact that a low volume of procedures correlates with lower cannulation rates and more complications. In an Austrian study by Kapral et al., the authors demonstrated a success rate of $86.9 \%$ with $10.2 \%$ of complications in hospitals performing more than 50 explorations per year, whereas institutions performing less than 50 ERCPs per year had a success rate of $80.3 \%$ with $13.6 \%$ of complications (12).

Therefore, the answer to the question regarding whether first- or second-level hospitals may assume ERCP performance is straightforward - If a hospital has endoscopists adequately trained for effective, safe ERCP, and their volume of ERCP procedures is also adequate (approximately 100 per year), there is no reason to hold back from granting them the involved privileges. In our country a number of "small" hospitals perform ERCPs with the required standards $(13,14)$.

In the current issue of this journal, the group of Hospital de Arganda del Rey (Madrid, Spain), a hospital with 115 beds, demonstrates how a difficult technique like ERCP may be successfully initiated in a hospital of these characteristics (1): Initially, an estimation of ERCP requirements was made, which suggested that an adequate number of procedures per year could be obtained. Later on, training was obtained at a referral center for doctors and nurses, who completed more than 180 procedures. Finally, ERCP was gradually implemented, and success and complication rates similar to those seen in high-volume institutions were reached on the second year; 126 procedures are performed annually, which may be considered an intermediate volume.

In summary, we may state that, in order to grant privileges for ERCP, a hospital should have: 
- Adequately trained endoscopists meeting the competency criteria recommended by international endoscopy societies; as with other techniques, aware of their technical limitations; and willing to refer complicated cases to hospitals endowed with more experience.

- To guarantee a minimum number of ERCPs each year in order to keep competency and to ensure adequate cost-effective benefits.

\section{ERCP in low-volume hospitals - Arguments against (Sarbelio Rodríguez-Muñoz)}

A long time ago, in a hospital located in a small region, an endoscopist, as inexperienced and arrogant as he was young, convinced their hospital Managing Director to buy a duodenoscope. The reasons argued by that endoscopist were probably similar to those posited by Riesco et al. (1) and the "for" part of the editorial. Today, without the arrogance of youth and having the experience brought by age and my last 22 years of working at a referral hospital with a high volume of ERCP procedures, I have been invited to cowrite this article in order to report not what I thought at age 33 but the benefits patients obtain when ERCPs are performed in a hospital like the one I am working for now.

Before performing a billiary procedure any endoscopist should answer as honestly as possible a number of questions. First comes the question "Why am I doing this?". If your answer differs from "Because I like it and enjoy myself doing it", you must stop your activity and refer your patients to someone else immediately, no matter if you perform 50 or 300 procedures per year. This is not an easy question - In a recent survey among ERCP endoscopists in the USA, only $58 \%$ of those working at institutions with fewer than 50 ERCPs per year answered to this question in the affirmative (10). The amount of personal stress experienced by an endoscopist with this technique is unlike that reported for any other procedure. The frustrating combination of a long learning curve, high morbidity and mortality rates, and frequent legal claims cannot be overstated. Experiencing this level of stress is unreasonable when one does not feel comfortable during the exploration, which occurs to $60 \%$ of endoscopists performing fewer than 50 ERCP procedures a year (10).

The second question derives from the first one - "Am I really capable of doing this technique?" In another 2011 survey among gastroenterology fellows in the USA (11), $74 \%$ stated that they had not performed during their training the 200 procedures recommended by ASGE or considered their training on this technique was inadequate. These answers are somewhat scary considering that $91 \%$ of these physicians had tried their hand at practising ERCPs within the year after finishing their fellowship. I have personally asked my former fellows whether they considered themselves capable of doing ERCP at fellowship completion, and their honest and sincere answer was "No" in all cases. It is a satisfactory answer to me because current training programs only allow that fellows be provided with 50 cases during their training, and honesty is also an important asset that needs to be learned during fellowship (15). Endoscopists performing ERCPs in our institution received specific, steady, dedicated training for at least one year before their first such procedure with no supervision by a "senior" endoscopist. So, is there a reason to worry? The answer is yes, because many of our younger endoscopists will end up working and doing ERCP in low-volume hospitals -as is the case with Riesco et al. (1)- with no experienced colleague to help them during this crucial period of training and maturing. No doubt, they will attain an adequate level of competency over time, but only after struggling themselves and with their patients. Moreover, will they then be able to progress and stay updated having a reduced number of cases per year? (16). 
At this point it is important to remember that ERCP has dramatically changed in the past two decades along with improvements in imaging techniques and billiary and pancreatic surgery. Because of this, the number of diagnostic ERCPs has decreased to almost zero (17), and there is no point in putting patients at risk when a safe surgical alternative is available $(18,19)$. At present, ERCP remains the firstchoice procedure for the treatment of most billiary and pancreatic diseases, and has become a therapeutic technique for accessing the bile duct and pancreas. Rather than simply an exam, ERCP is in itself a path open for treatment delivery. However, both cannulation and therapy will benefit from the presence of an expert $(12,20-25)$ and all the facilities provided by a tertiary referral center. This is the next question an endoscopist should answer before jumping into ERCP: "Am I offering the best of options to this specific patient?"

First of all, a selective, deep cannulation of the desired duct is the first step in every ERCP, and a limiting factor influenced by experience and daily training. Cannulation rate progressively raises with the number of exams performed, and reaches a minimum competency level (cannulation rate over $80 \%$ ) after 650 ERCPs (300 for basic training in complexity levels 1 and 2, and an additional 350 for adequate training in levels 3 and 4) (16). These numbers may represent over 10 years of work in a low-volume hospital. Furthermore, cannulation rates for a naïve papilla are higher in referral centers than in low-volume institutions. For this reason, patients cared for in low-volume hospitals are being offered a suboptimal therapy upfront, and we should justify it. Not every patient will be treated by an expert, but what cut-off should we accept when the cannulation rate an expert achieves is as high as $95 \%$ ? We should probably accept $80 \%$ for a novel ERCPist $(7,26-28)$. But, would our patients accept that 1 out of 5 will run the risks of ERCP without any possibility of success except in an emergency with no other alternative? If I were the patient, and I believe most readers will agree on this, I would not accept that. Patients assume that their local gastroenterologists are adequately trained and success rates are similar to those of colonoscopy, and this may not be the case. As for colonoscopy, the success rate achieved by experts may be confusing, and clinical practices in the real world may differ. As an example, perhaps we remember the wide variability reported for cecal intubation. I am afraid that, in the case of ERCP, this may be even more surprising - we may have experts in lowvolume hospitals with cannulation rates higher than $95 \%$ (29), and novel ERCPists in high-volume centers who have not attained such degree of competence yet.

Secondly, some patients undergoing ERCP might benefit from a multidisciplinary approach and the technology available at tertiary centers. Along these same lines, it is clear that a dedicated endoscopist has better chances of keeping up-to-date than a general gastroenterologist, who must spend time in different areas of patient care on a daily basis. A lack of methodology and equipment may lead to errors in diagnostic strategy and patient selection for this technique. Furthermore, the diagnosis and treatment of ERCP complications may be delayed (16). This will certainly be bad for the patient and expensive for our health care system.

Finally, technology resources available at an endoscopy unit in a tertiary center are usually better than in smaller institutions, having dedicated instruments for complex situations, e.g. stents, cholangioscope, pancreatic therapy, and intraductal/extracorporeal lithotripsy. At this point we may figure out that differences exist in research between these two institution types - technology, recruitment time, and statistical significance. Obviously, patients treated in smaller institutions are being denied all these possibilities in a first attempt. And things may even get worse when endoscopists in low-volume institutions are reluctant to refer patients after a failed ERCP. 
We all agree that a failed ERCP -which will more likely occur in a low-volume hospital- is surely frustrating to the endoscopist, disappointing and dangerous for the patient, and likely associated with a significant cost increase derived from the procedures required to treat the ensuing complications. Also, we must keep in mind that severe complications are 20 times more common after ERCP as compared to colonoscopy, and that $1 \%$ of patients suffering from said complications will remain in hospital for months or will eventually die as a result of an ERCP-related pancreatitis or perforation (16).

Having said this, I do not mean that the number of billiary endoscopists in Spain should be restricted to 277 (the number estimated for a population of $46,116,779$ people) $(16,20,30-32)$, and I do not advocate to forbid ERCP performance to endoscopists adequately trained wherever they work; what I would like to emphasize is that we should always consider what is best for every individual patient and for the health care system in which we work. If we cannot group patients, improve efficacy and effectiveness, and reduce costs, there will be no happy end for anyone (patients, physicians, economic advisors) regardless of hospital type, which will be extremely difficult to explain to coming generations.

Leopoldo López-Rosés ${ }^{1}$, Sarbelio Rodríguez-Muñoz ${ }^{2}$, Enrique Vázquez-Sequeiros ${ }^{3}$ and J. Enrique Domínguez-Muñoz ${ }^{4}$

${ }^{1}$ Department of Digestive Diseases. Hospital Universitario Lucus Augusti. Lugo, Spain. ${ }^{2}$ Department of Gastroenterology. Hospital 12 de Octubre. Madrid, Spain. ${ }^{3}$ Department of Gastroenterology. Hospital Ramón y Cajal. Madrid. Universidad de Alcalá, IRYCIS. Spain. ${ }^{4}$ Department of Gastroenterology. Hospital Clínico. Santiago Compostela. A Coruña, Spain

\section{REFERENCES}

1. Riesco López JM, Vázquez Romero M, Rizo Pascual JM, Rivero Fernández M, Manzano Fernández R, González Alonso R, et al. Efficacy and safety of ERCP in a low-volume hospital. Rev Esp Enferm Dig 2013;105(2):68-73.

2. Eisen GM, Dominitz JA, Faigel DO, Goldstein JL, Kalloo AN, Petersen BT, et al. Guidelines for advanced endoscopic training. Gastrointest Endosc 2001;53(7):846-8.

3. Isaacs P. Endoscopic retrograde cholangiopancreatography training in the United Kingdom: A critical review. World J Gastrointest Endosc 2011;3(2):30-3.

4. Hellier MD, Morris AI. ERCP training. Time for change. Gut 2000;47:459-460.

5. Verma D, Gostout CJ, Petersen BT, Levy MJ, Baron TH, Adler DG. Establishing a true assessment of endoscopic competence in ERCP during training and beyond: a single-operator learning curve for deep biliary cannulation in patients with native papillary anatomy. Gastrointest Endosc 2007:65(3):394-400.

6. Ang TL, Cheng J, Khor JLC, Mesenas SJ, Vuk FC, Wong WK. Guideline on training and credentialing in endoscopic retrograde cholangiopancreatography. Singapore Med J 2011;52(9):654-7.

7. Jowell PS, Baillie J, Branch MS, Affronti J, Browning CL, Bute BP. Quantitative assessment of procedural competence. A prospective study of training in endoscopic retrograde cholangiopancreatography. Ann Intern Med 1996;15;125(12):983-9.

8. Harewood GC, Baron TH. An assessment of the learning curve for precut biliary sphincterotomy. Am J Gastroenterol 2002;97(7):1708-12.

9. Akaraviputh T, Lohsiriwat V, Swangsri J, Methasate A, Leelakusolvong S, Lertakayamanee N. The learning curve for safety and success of precut sphincterotomy for therapeutic ERCP: A single endoscopist s experience. Endoscopy 2008;40(6):513-6.

10. Cote GA, Keswani RN, Jackson T, Fogel E, Lehman GA, McHenry L, et al. Individual and practice differences among physicians who perform ERCP at varying frequency: a nationwide survey. Gastrointest Endosc 2011;74(1):65-73.

11. Kowalski T, Kanchana T, Pungpapong S. Perceptions of gastroenterology fellows regarding ERCP competency and training. Gastrointest Endosc 2003;58(3):345-9.

12. Kapral C, Duller C, Wewalka F, Kerstan E, Vogel W, Schreiber F. Case volume and outcome of endoscopic retrograde cholangiopancreatography: Results of a nationwide Austrian benchmarking project. Endoscopy 2008;40(8):625-30. 
13. Ciriza C, Dajil S, Jiménez C, Urquiza O, Karpman G, García MJ. Five-year analysis of endoscopic retrograde cholangiopancreatography in the Hospital del Bierzo. Rev Esp Enferm Dig 1999;91(10):693-702.

14. García-Cano Lizcano J, González Martín JA, Morillas Ariño J, Pérez Sola A. Complications of endoscopic retrograde cholangiopancreatography. A study in a small ERCP unit. Rev Esp Enferm Dig 2004;96(3):163-73.

15. Sivak MV. Trained in ERCP. Gastrointest Endosc 2003;58:412-14.

16. Cotton PB. Are low-volume ERCPists a problem in the United States? A plea to examine and improve ERCP practice —-Now. Gastrointest Endosc 2011;74:161-6.

17. Cohen S, Bacon BR, Berlin JA, Fleischer D, Hecht GA, Loehrer PJ, et al. National Institutes of Health Stateof-the-Science Conference Statement: ERCP for diagnosis and therapy, January 14-16, 2002. Gastrointest Endosc 2002;56:803-9.

18. Dite P, Ruzicka M, Zboril V, Novotný I. A prospective, randomized trial comparing endoscopic and surgical therapy for chronic pancreatitis. Endoscopy 2003;35:553-8.

19. Cahen DL, Gouma DJ, Nio Y, Rauws EA, Boermeester MA, Busch OR, et al. Endoscopic versus surgical drainage of the pancreatic duct in chronic pancreatitis. N Engl J Med 2007;356:676-84.

20. Enochsson L, Swahn F, Arnelo U, Nilsson M, Löhr M, Persson G. Nationwide, population-based date from 11,074 ERCP procedures from the Swedish Registry for gallstone surgery and ERCP. Gastrointest Endosc 2010;72:1175-84

21. Loperfido S, Angelini G, Benedetti G, Chilovi F, Costan F, De Berardinis F, et al. Major early complications from diagnostic and therapeutic ERCP: a prospective multicenter study. Gastrointest Endosc 1998;48:1-10

22. Freeman ML, Nelson DB, Sherman S, Haber GB, Herman ME, Dorsher PJ, et al. Complications of endoscopic biliary sphincterotomy. N Engl J Med 1996:335:909-18.

23. Rabenstein T, Schneider HT, Nicklas M, Ruppert T, Katalinic A, Hahn EG, et al. Impact of skill and experience of the endoscopist on the outcome of endoscopic sphincterotomy techniques. Gastrointest Endosc 1999;50:62836.

24. Davis WZ, Cotton PB, Arias R, Williams D, Onken JE. ERCP and sphincterotomy in the context of laparoscopic cholecystectomy: Academic and community practice patients and results. Am J Gastroenterol 1997;92:597601.

25. Varadarajulu S, Kilgore ML, Wilcox CM, Eloubeidi MA. Relationship among hospital ERCP volume, length of stay, and technical outcomes. Gastrointest Endosc 2006;64:338-47.

26. Baron TH, Petersen BT, Mergener K, Chak A, Cohen J, Deal SE, et al. Quality indicators for endoscopic retrograde cholangiopancreatography. Gastrointest Endosc 2006;63(Supl. 4):29-34.

27. Cotton PB, Hawes RH, Barkun A, Ginsberg GG, Amman S, Cohen J, et al. Excellence in endoscopy: toward practical metrics. Gastrointest Endosc 2006;63:286-91.

28. Eisen GM, Baron TH, Dominitz JA, Faigel DO, Goldstein JL, Johanson JF, et al. Methods of granting hospita privileges to perform gastrointestinal endoscopy. Gastrointest Endosc 2002;55:780-3.

29. García-Cano J, Reyes Guevara AK, Martínez Pérez T, Valiente González L, Martínez Fernández R, Viñuelas Chicano M, et al. Prótesis metálicas autoexpandibles totalmente recubiertas en el tratamiento de coledocolitiasis difíciles. Rev Esp Enferm Dig 2013;105:7-12.

30. Mazen Jamal M, Yoon EJ, Saadi A, Sy TY, Hashemzadeh M. Trends in the utilization of endoscopic retrograde cholangiopancreatography (ERCP) in the United States. Am J Gastroenterol 2007;102:966-75.

21. Allison MC, Ramanaden DN, Fouweather MG, Davis DK, Colin-Jones DG. Provision of ERCP services and training in the United Kingdom. Endoscopy 2000;32:693-9.

32. Hilsden RJ, Romagnuolo J, May GR. Patterns of use of endoscopic retrograde cholangiopancreatography in a Canadian province. Can J Gastroenterol 2004;18:619-24. 